\title{
A COMPARATIVE STUDY OF TOPICAL BETAXALOL AND TIMOLOL FOR THEIR EFFICACY AND SIDE EFFECTS
}

\author{
Shobhana Jorvekar, Mallikarjun Salagar, Akshay Bhandari. \\ Department of Ophthalmology, Rural Medical College, \\ Pravara Institute of Medical Sciences, Loni, Ahmednagar, Maharashtra, India.
}

\section{ABSTRACT}

Purpose: Primary open angle glaucoma (POAG) is one such field in Ophthalmology where ophthalmologists have failed to stop blindness due to it. All the available treatment modalities are directed towards the reduction of intraocular pressure (IOP) but without interfering the basic aetiopathogenesis. In this study we propose to study efficacy, potency and adverse effects of topical Timolol and Betaxalol in primary open angle glaucoma. Methodology: A comparative study of topical Betaxalol $0.5 \%$ and Timolol $0.5 \%$ in the management of POAG was conducted at Tertiary care hospital. Fifty patients of newly diagnosed POAG of different age, sex, religion from both urban and rural population attending eye OPD were included in this study. 25 patients were treated with topical Timolol maleate $0.5 \%$ ophthalmic solution BD and 25 patients were treated with topical $0.5 \%$ Betaxalol hydrochloride phthalmic solution BD. At 20 weeks follow up IOP levels $n$ both the groups measured by applanation tonometer were compare to each other. Results: In this study a total of 50 patients with POAG were studied. 25 patients were treated with Timolol maleate $0.5 \%$ ophthalmic solution and 25 patients were treated with $0.5 \%$ Betaxalol hydrochloride ophthalmic solution. Out of 50 patients, 29 (58\%) were male and 21(42\%) were female patients. POAG was most common in the age group of 51-60 years with average age 51.50 (S.D. 9.8) years. Average age in males was 54.50 years, while in female it was 49.31 years. Conclusion: both Timolol and Betaxalol are effective in decreasing IOP in POAG patients. The magnitude of Timolol in decreasing IOP is more as compared to Betaxalol. The selective beta 1 adrenergic inhibition of Betaxalol provides an added benefit for those patients in whom beta 2 blockade could be harmful.

KEYWORDS: Primary open angle glaucoma; Timolol; Betaxalol; Blindness.

\section{INTRODUCTION}

Eye is that special sense of organ, which makes an individual physically, mentally, socially and economically effective. Loss of function of the eye is blindness. Blindness is a common and distressing complication of glaucoma. It accounts for blindness in 5 million population of which 3 million is due to primary open angle glaucoma (POAG) throughout the world.[1]

Primary open angle glaucoma is one such field in Ophthalmology where ophthalmologists have failed to stop blindness due to it. Despite of much experimental, clinical and even speculative work, the aetiology of primary open angle glaucoma still remains obscure and hence, treatment is just empirical.[2] All the available treatment modalities are directed towards the reduction of intraocular pressure (IOP) but without interfering the

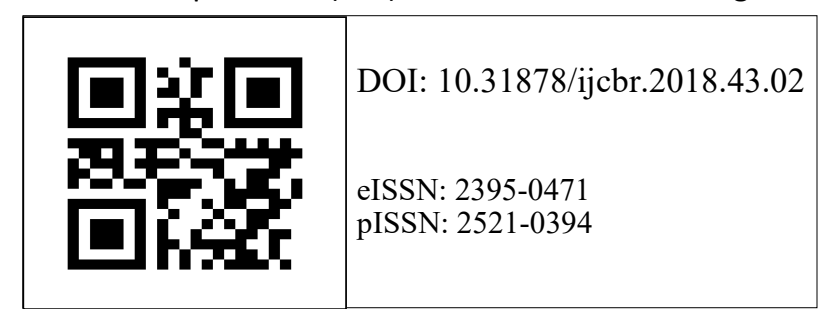

basic aetiopathogenesis. Hence at the most blindness due to primary open angle glaucoma is delayed, but not eradicated in present study. As the functional damage in glaucomatous eye is attributed to elevated intraocular pressure, the basic aim of treating glaucoma whether medical, surgical or laser is to control the intraocular pressure. $[3,4,5]$ Primary open angle glaucoma being a slowly progressive disease remains asymptomatic in more than $50 \%$ of patients till gross diminution of vision or field occurs. 1 In such a situation, to the patients laser or surgical therapy may sound high for the disease. This is one of the reasons for the acceptability of medical therapy apart from other modalities being still under long term study.[5,6] Among the available drugs, there is always a constant search for the best in terms of efficacy, safety and economy.[7] The commonly used drugs in the treatment of primary open angle glaucoma are beta adrenergic antagonists. $[8,9,10]$ Beta blockers reduce the IOP by decreasing aqueous humor formation. The most commonly used drugs in this group are Timolol and Betaxalol.

Objectives: The effectiveness of topical Timolol 0.5\% and topical Betaxalol $0.5 \%$ in controlling raised IOP in POAG as well as to observe the side effects of these

Correspondence: Dr. Bhandari Akshay Jawaharlal. Department of Ophthalmology, Pravara Institute of Medical Sciences and Rural Medical College, Loni, Ahmednagar, Maharashtra, India. Email: kiwis143@gmail.com 
drugs.

In this study we proposed to study efficacy, potency and adverse effects of topical Timolol and Betaxalol in primary open angle glaucoma.

\section{MATERIALS AND METHODS}

Study design: An analytical observational study

Ethics approval: Ethical clearance was taken from Institutional ethical board. For the eligible patients, written informed consent was taken.

\section{Sample size: Fifty patients of newly diagnosed POAG}

Inclusion criteria: different age, sex, religion from both urban and rural population attending eye OPD patients with elevated IOP (IOP more than $20 \mathrm{~mm}$ of $\mathrm{Hg}$ ) with or without glaucomatous disc or field damage with open anterior chamber angle were included in this study.

Exclusion criteria: Patients with hypersensitivity to components of study drugs, active ocular infection or inflammatory disorders, history of any acute or progressive retinal disorders, use of contact lenses, history of previous intraocular surgery, bronchial asthma, chronic obstructive pulmonary disease and pregnancy or lactation were excluded from the study.

Intraocular pressure was recorded with Goldman applanation tonometer under topical anaesthesia.

Group: Total 50 patients were studied. They were divided into 2 groups

Group A: 25 patients with POAG who were treated by Timolol maleate $0.5 \%$.

Group B: 25 patients with POAG who were treated by Betaxalol hydrochloride $0.5 \%$.

Methodology: In this study a total of 50 patients with POAG were studied. 25 patients were treated with topical Timolol maleate $0.5 \%$ ophthalmic solution BD and 25 patients were treated with topical $0.5 \%$ Betaxalol hydrochloride phthalmic solution BD. At 20 weeks follow up IOP levels $n$ both the groups measured by applanation tonometer were compare to each other, Changes in the visual acuity, Visual field changes, optic disc changes and adverse effects were studied at every week. Statistical analysis: Data analysis was done by chi square test.

\section{RESULTS}

Out of 50 patients, 29 (58\%) were male and 21(42\%) were female patients. POAG was most common in the age group of 51-60 years with mean age of $51.50 \pm 9.8$ S.D years. Average age in males was 54.50 years, while in female it was 49.31 years. (Table 1 )

In Timolol maleate group mean baseline intraocular pressure was 28.60 (S.D. 1.75) $\mathrm{mm} \mathrm{Hg}$. These patients were treated with $0.5 \%$ Timolol maleate. The mean IOP after 20 weeks treatment was 19.96 (S.D. 1.76) $\mathrm{mm} \mathrm{Hg}$ and the mean reduction in IOP was $8.64 \mathrm{~mm} \mathrm{Hg}$ which is highly significant $(P<0.001)$. (Table 2$)$

In Betaxalol hydrochloride group mean baseline intraocular pressure was 27.84 (S.D. 1.61) $\mathrm{mm} \mathrm{Hg}$. These patients were treated with $0.5 \%$ Betaxalol hydrochloride. The mean IOP after 20 weeks treatment was 20.28 (S.D. 1.33) $\mathrm{mm} \mathrm{Hg}$ and the mean reduction in IOP was $7.56 \mathrm{~mm} \mathrm{Hg}$ which is highly significant $(P<0.001)$. (Table 2)

At 20 weeks out of 25 patients receiving Timolol maleate 2 patients showed decrease in visual acuity by one Snellen's line. In the Betaxalol hydrochloride group, only one patient showed decrease in visual acuity by one Snellen's line. (Table 3)

In our study, it was very difficult to evaluate the visual fields in the class of patients (poor and literate) studied. Also the presence of lenticular opacities interfered with correct assessment of visual fields. There was no change in the visual fields throughout the study period in either group. (Table 4) In both the study groups we found no change in the cup disc ratio in any patients. (Table 5)

Of 25 patients who received Timolol maleate, 2 patients $(8 \%)$ developed mild stinging after instillation of the drug, while in the Betaxalol hydrochloride group 8 patients (32\%) complained of mild to moderate stinging for few minutes after instillation of the test drug. In either group discontinuation of the drug was not required. In Timolol maleate group 4 patients (16\%) complained of discomfort and tearing was seen in 3 patients (12\%). Only one patient (4\%) complained of photophobia. In Betaxalol hydrochloride group one patient (4\%) complained of itching and 7 patients (28\%) complained of discomfort. (Table 6).

Table 1. Age and sex wise distributions of $\mathbf{5 0}$ patients

\begin{tabular}{|c|c|c|c|}
\hline \multirow{2}{*}{ Age in years } & \multicolumn{2}{|c|}{ Sex } & \multirow{2}{*}{ Total } \\
\cline { 2 - 3 } & Male & Female & \\
\hline $11-20$ & 0 & 1 & 1 \\
\hline $21-30$ & 0 & 1 & 1 \\
\hline $31-40$ & 1 & 2 & 3 \\
\hline $41-50$ & 9 & 4 & 13 \\
\hline $51-60$ & 15 & 11 & 26 \\
\hline $61-70$ & 4 & 2 & 6 \\
\hline Total & 29 & 21 & 50 \\
\hline Percentage & $58 \%$ & $52 \%$ & \\
\hline
\end{tabular}


Table 2. Distribution of mean IOP (in $\mathrm{mm} \mathrm{Hg}$ )

\begin{tabular}{|c|l|l|}
\hline Observation & $\begin{array}{c}\text { Timolol maleate } \\
\text { group }\end{array}$ & \multicolumn{1}{|c|}{$\begin{array}{c}\text { Betaxalol hydro- } \\
\text { chloride group }\end{array}$} \\
\hline Baseline & 28.60 & 27.84 \\
\hline $1^{\text {st }}$ week & 20.68 & 21.72 \\
\hline $2^{\text {nd }}$ week & 19.92 & 20.98 \\
\hline $4^{\text {th }}$ week & 19.58 & 20.62 \\
\hline $8^{\text {th }}$ week & 19.24 & 20.26 \\
\hline $12^{\text {th }}$ week & 19.92 & 20.62 \\
\hline $16^{\text {th }}$ week & 19.94 & 20.28 \\
\hline $20^{\text {th }}$ week & 19.96 & 20.28 \\
\hline
\end{tabular}

Table 3. Changes in the visual acuity in this study

\begin{tabular}{|c|c|c|c|c|}
\hline \multirow[t]{2}{*}{ Visual acuity } & \multicolumn{2}{|c|}{$\begin{array}{c}\text { Timolol maleate } \\
\text { group }\end{array}$} & \multicolumn{2}{|c|}{$\begin{array}{l}\text { Betaxalol hydro- } \\
\text { chloride group }\end{array}$} \\
\hline & $\begin{array}{c}\text { On } \\
\text { admis- } \\
\text { sion }\end{array}$ & $\begin{array}{l}20^{\text {th }} \\
\text { week }\end{array}$ & $\begin{array}{c}\text { On } \\
\text { admis- } \\
\text { sion }\end{array}$ & $\begin{array}{l}20^{\text {th }} \\
\text { week }\end{array}$ \\
\hline $6 / 6$ & 2 & 2 & 3 & 3 \\
\hline $6 / 9$ & 6 & 6 & 5 & 5 \\
\hline $6 / 12$ & 2 & 2 & 4 & 4 \\
\hline $6 / 18$ & 4 & 4 & 3 & 3 \\
\hline $6 / 24$ & 3 & 3 & 2 & 1 \\
\hline $6 / 36$ & 2 & 2 & 1 & 2 \\
\hline $6 / 60$ & 2 & 2 & 4 & 4 \\
\hline FC 5 meter & 1 & 0 & 1 & 1 \\
\hline FC 4 meter & 0 & 1 & 1 & 1 \\
\hline FC 3 meter & 1 & 0 & 0 & 0 \\
\hline FC 2 meter & 1 & 1 & 1 & 1 \\
\hline FC 1 meter & 0 & 1 & 0 & 0 \\
\hline PL PR (+) & 1 & 1 & 0 & 0 \\
\hline Total & 25 & 25 & 25 & 25 \\
\hline
\end{tabular}

Table 4. Observation showing visual field changes in this study

\begin{tabular}{|c|c|c|}
\hline $\begin{array}{c}\text { Observa- } \\
\text { tion }\end{array}$ & $\begin{array}{c}\text { Timolol maleate } \\
\text { group }\end{array}$ & $\begin{array}{c}\text { Betaxalol hydro- } \\
\text { chloride group }\end{array}$ \\
\hline $1^{\text {st }}$ week & No changes & No changes \\
\hline $2^{\text {nd }}$ week & No changes & No changes \\
\hline $4^{\text {th }}$ week & No changes & No changes \\
\hline $8^{\text {th }}$ week & No changes & No changes \\
\hline $12^{\text {th }}$ week & No changes & No changes \\
\hline $16^{\text {th }}$ week & No changes & No changes \\
\hline $20^{\text {th }}$ week & No changes & No changes \\
\hline
\end{tabular}

Table 5. Observation showing optic disc changes in this study

\begin{tabular}{|c|c|c|}
\hline $\begin{array}{c}\text { Observa- } \\
\text { tion }\end{array}$ & $\begin{array}{c}\text { Timolol maleate } \\
\text { group }\end{array}$ & $\begin{array}{c}\text { Betaxalol hydro- } \\
\text { chloride group }\end{array}$ \\
\hline $1^{\text {st }}$ week & No changes & No changes \\
\hline $2^{\text {nd }}$ week & No changes & No changes \\
\hline $4^{\text {th }}$ week & No changes & No changes \\
\hline $8^{\text {th }}$ week & No changes & No changes \\
\hline $12^{\text {th }}$ week & No changes & No changes \\
\hline $16^{\text {th }}$ week & No changes & No changes \\
\hline $20^{\text {th }}$ week & No changes & No changes \\
\hline
\end{tabular}

Table 6. Ocular adverse effects in this study

\begin{tabular}{|c|c|c|}
\hline Adverse effect & $\begin{array}{c}\text { Timolol male- } \\
\text { ate group }\end{array}$ & $\begin{array}{c}\text { Betaxalol hydro- } \\
\text { chloride group }\end{array}$ \\
\hline Stinging or & 2 & 8 \\
\hline Discomfort & 4 & 7 \\
\hline Itching & 0 & 1 \\
\hline Tearing & 3 & 0 \\
\hline Photophobia & 1 & 0 \\
\hline
\end{tabular}

\section{DISCUSSION}

Medical therapy is usually the first line of approach in POAG. The mainly used drugs in the treatment of POAG are beta adrenergic blockers.[3] Beta adrenergic blockers reduce IOP by decreasing aqueous formation.[4] In this study a total of 50 patients with POAG were studied. 25 patients were treated with $0.5 \%$ Timolol maleate ophthalmic solution and 25 patients were treated with $0.5 \%$ Betaxalol hydrochloride solution.

In the follow up after 20 week, the decrease in IOP were highly significant $(P<0.001)$ with Timolol. The decrease in IOP was $30.21 \%$. David P. Berry et al compared topical Timolol and Betaxalol in 46 patients for 26 weeks. They found the percentage reduction of IOP was 33.2\% in Timolol group.5 Robert H. Stewart et al, in their study of comparison of Timolol and Betaxalol in 29 patients found reduction of IOP by $8.4 \mathrm{~mm} \mathrm{Hg}$ $(29 \%) .[6,7]$ These results are similar to our study.

In the follow up after 20 week, the decrease in IOP were highly significant $(P<0.001)$ with betaxalol. The decrease in IOP was $7.56 \mathrm{~mm} \mathrm{Hg}(27.15 \%)$. Our findings are nearer to previous studies by David P. Berry et al, who showed $28.9 \%$ reduction in IOP5 and Robert $\mathrm{H}$. Stewart et al, who showed $7.6 \mathrm{~mm} \mathrm{Hg} \mathrm{(26 \% )} \mathrm{average}$ reduction in Betaxalol group.[6]

At 20 weeks out of 25 patients receiving Timolol maleate 2 patients showed decrease in visual acuity by one 
snellen's line. In the Betaxalol group hudrochloride group, only one patient showed decrease in visual acuity by one snellens line. Decrease in visual acuity could be attributed to progressive lenticular changes in all 3 patients. Not even a single case showed sudden loss of vision. David P. Berry et al compared 0.5\% Timolol and 0.5\% Betaxalol in 46 patients with POAG.[5] They did not find any visual acuity changes in both these groups. According to Robert $\mathrm{H}$. Stewart et al no change in visual acuity was seen in either group in their six-month double blind comparative study of Betaxalol and timolol involving 29 patients.[6] These observations are similar to our findings. In our study there was no change in the visual fields throughout the study period in either group. Our findings are similar to other studies.

In both the study groups we found no change in the cup disc ratio in any patients. Our findings are in accordance with the previous studies.

\section{CONCLUSION}

In the light of these results, we conclude that both Timolol and Betaxalol are effective in decreasing IOP in POAG patients. The magnitude of Timolol in decreasing IOP is more as compared to Betaxalol. The selective beta 1 adrenergic inhibition of Betaxalol provides an added benefit for those patients in whom beta 2 blockade could be harmful.

\section{REFERENCES}

1. Adler F: Physiology of the eye, 9th edition, 1992.

2. Allen Robert. C, Hertzmark E Ilen, Alexandes. M et al; A double masked comparison of Betaxalol and Timolol in the treatment of open angle glaucoma. Am J Oohthalmol.101: 535-541; May 1986.

3. Messemer C, Flammer Stumpung D: Influence of Betaxalol and Timolol on the visual fields of patients with glaucoma. Am J Ophthalmol.112:678-681, Dec 1991.

4. Zimerman Thom J, Kass Micheal A: Timolol Maleateefficacy and safety. Arch Ophthalmol. Vol 97: 656658, Apr 1979.

5. Berry David P, Buskirk Van E. M, Shields Bruce M: Betaxalol and Timolol. A comparison of efficacy and side effects. Arch Ophthalmol. Vol.102: 42-45, Jan 1984.

6. Stewart - Robert H, Kimbrogh Richard L. Ward, Richard L: Betaxalol Vs Timolol- a six month double blind comparison. Arch Ophthalmol. Vol 104: 46-48, Jan 1986.

7. Hutzelmann J, Owens S, Shedden A, Adamsons
I,Vargas Eand the International clinical equivalence study group. Comparison of the safety and efficacy of fixed combination of Dorzolamide/Timolol and the concomimitant administration of Dorzolamide and Timolol: A clinical equivalence study. $\mathrm{Br} \mathrm{J}$ Ophthalmol 1998; 82: 1249-53.

8. Shields MB. The intraocular pressure. In. Text Book of Glaucoma 2nd edition. Mosby-Year Book, 1987. pp 60.

9. West RD, Lischwe DT, Thompson MV, Ide HC. Comparative efficacy of the beta- blockers for the prevention of increased IOP after cataract extraction. Am J Ophthalmol 1988; 106: 168-73.

10. Feghali GJ, Kaufman LP. Decreased IOP in the hypertensive human eye with betaxolol, a beta-1 aderanergic antagonist. Am J Ophthalmol 1985; 100: 777 $-82$.

How to Cite this article: Shobhana Jorvekar, Mallikarjun Salagar, Akshay Bhandari. Electromyographic A comparative study of topical betaxalol and timolol for their efficacy and side effects. Int. j. clin. biomed. res. 2018;4(3): 6-9. 